\title{
Geo-spatial Assessment of Land Use/Land Cover (LU/LC) Dynamics in Akoko South West Local Government, Ondo State, Nigeria
}

\author{
Dada Ibilewa ${ }^{1 *}$, Mustapha Aliyu ${ }^{1}$, Usman O. Alalu ${ }^{1}$ \\ and Taiwo Hassan Abdulrasheed ${ }^{2}$
}

${ }^{1}$ National Space Research and Development Agency, Abuja, Nigeria.

${ }^{2}$ Federal University of Technology, Minna, Nigeria.

\begin{abstract}
Authors' contributions
This work was carried out in collaboration among all authors. All authors read and approved the final manuscript.

Article Information

DOI: $10.9734 / A J G R / 2021 / v 4 i 395$

Editor(s):

(1) Dr. Xu Chong, Institute of Geolog, China.

Reviewers:

(1) Susan Ngwira, University of Livingstonia, Malawi.

(2) Rowena R. Sazon, President Ramon Magsaysay State University, Philippines. Complete Peer review History: https://www.sdiarticle4.com/review-history/73461
\end{abstract}

Original Research Article

Received 29 June 2021

Accepted 09 September 2021

Published 16 September 2021

\begin{abstract}
Geo-spatial assessment of land use/cover dynamics in Akoko South West Local Government was instigated to bridge the knowledge gap created by data deficiency on the nature, scope and magnitude of land use/cover change in the area. This was done through the analysis of Landsat images of three epochs from 2000 through 2010 to 2020. The processing of the satellite images was done in ArcGIS 10.8 while the analysis and 2030 projection was done in Microsoft office excel using the result from the analysis. QGIS was used to remove the scan lines error on the 2010 image. The result showed increasing built-up area, reducing vegetation and farmlands and diminishing rock outcrops. The changes vary among the different classification characteristics. The increasing change in the second epoch was higher in built up areas while rock outcrops increased in the first epoch. Farmland and vegetation were on reducing trend throughout the study period. However, the moderate change observed in the second epoch for the two land cover classes were not as significant as the first epoch. Government policies on forest reserve should strictly be adhered to in order to preserve the vegetation in the area. People of the area should be advised to diversify their economy in order to avoid total dependence on the forest reserve.
\end{abstract}


Keywords: Vegetation; farmland; reserve; Geo-spatial; assessment; built up; rock outcrop.

\section{INTRODUCTION}

Land uses are the different types of activities that are carried out on land by anthropogenic activities while land cover is defined by the biophysical attributes of land (natural vegetation, water bodies, rock/soil, sand and wastelands) that have an effect on ecosystem process [1]. Land use/land cover (LU/LC) which are mostly influenced by economic, political, cultural and land tenure factors are interconnected and interchangeable in nature.

FAO [2] sum up the whole gamut about land use and land cover as any delineable area of the earth's terrestrial surface, involving all attributes of the biosphere above or below this surface, including those of the near-surface climate, the soil and terrain forms, the surface hydrology (including shallow lakes, rivers, marshes and swamps), near-surface layers and associated ground water and geo-hydrological reserve, the plant and animal populations, the human settlement pattern and physical results of past and present human activity (terracing, water storage or drainage structures, roads and buildings). FAO [2] defined Land Cover (LC) as the "observed (bio) physical cover of the earth's surface", and is a synthesis of the many processes taking place on the land. It reflects land occupation (and its transformation) by various natural, modified or artificial systems and to some extent how these systems affect the land. LC is one of the most easily detectable indicators of human intervention on land. Because it can change quickly over time, it is also a good proxy for dynamics of the earth surface resulting from a variety of drivers and factors.

Land use and land cover change has become a central component in current strategies for managing natural resources and monitoring environmental changes (Kaul and Sopan, 2012). Land use and landcover change (LULC) analysis is essential to understand several environmental processes and social phenomenon as these changes reflect major changes on the Earth's land surface [3]. The changes have a multiplier effect on natural resource availability, ecosystem/landscape services and biodiversity [4].

Remotely sensed data from aerial photographs or satellite images are now being used for mapping land use and land cover changes.
Remote Sensing, which is not a solution in itself but only a means to an end, has become a powerful tool in both survey and evaluation of land resources, monitoring changes in the atmosphere and overall land utilization [5]. The detection of land use changes both in the urban and rural areas can be done much faster with the aid of data gathered from Remote Sensing devices, which can be manipulated and subjected to digital analysis. The technique has created unprecedented opportunities for nations to undertake proper inventories and evaluation of their resources; make appropriate plan for their utilization as well as monitor both natural and human-induced changes in the environment [5].

Satellite data have a number of advantages over conventional methods [6]. They provide regular and repetitive coverage; thus, the required information can often be simply extracted from them. The data are available in digital format and so can be used directly in digital cartographic production systems. Data costs are often much less and the cost of establishing ground control is much easier. They are also used to gather information on inaccessible terrain [7].

There is a significant change on LC/LU across the globe due to the climatic changes, rapid increase in population and over demand of the growing economic Minerals [6]. As a result of this change, land use systems need thorough systematic monitoring and management to maintain food security, minimize deforestation, conservation of biological diversity and protection of natural resources. It is necessary to enhance human occupation to the changing social, economic and natural environmental conditions. Rapid increase in population demands for more food, fodder and fuel wood. This has led to large scale environmental degradation and ecological imbalance. In order to use land optimally, it is necessary to have firsthand information about the existing land use/land cover (LU/LC) patterns [6].

\section{STATEMENT OF THE PROBLEM}

Akoko South West Local Government Area of Ondo State has undergone tremendous growth and development since inception [8]. This has resulted in increased modification and alterations in the status of its land use land cover over time. This change has continued without any attempt at documentation or comprehensive evaluation to 
know the magnitude and status. This study was . instigated to bridge the huge data gap by. evaluating the rate of change in the Locaß. Government Area from year 2000 to 2020 with a view to predict the projected change in the future. The product of the study will provide a baseline information to policy makers on the status of the LU/LC in the study area [9-11].

\section{OBJECTIVES OF THE STUDY}

The study aims to produce the land use land cover map of Akoko South West Local Government area at different epochs to evaluate the changes and predict the future land use/landcover change in the area. This was pursued through the following objectives:

To produce the land use/land cover map of the study area.

To determine the nature and scope of change through the analysis of the map produced above
To predict the future change in the area

To evaluate the implication of the change on the overall socio-economic development of the area.

\subsection{Study Area}

Akoko South West Local Government is one of the eighteen local government areas in Ondo State with the administrative headquarters in Oka Akoko. It is located between longitude $5^{0} 31^{1}$ $11^{11} \mathrm{E}$ to $5^{0} 49^{1} 55^{11} \mathrm{E}$ and latitude $7^{0} 18^{1} 52^{11} \mathrm{~N}$ to $7^{0} 31^{1} 3^{11} \mathrm{~N}$ with an area of $481 \mathrm{~km}^{2}$. The population was 239, 486 according to 2006 population census and projected to be 313,163 and 347, $590(174,619$ males and 172,971 females) in 2017 and 2021 respectively by the National Population Commission. The Local government falls under the tropical savannah climate with an estimated humidity of $60 \%$ and average temperature of $28^{\circ} \mathrm{C}$. The rainfall average is about $1700 \mathrm{~mm}$. The major occupation in the area is agriculture. Trading is a common economic activity among the women.

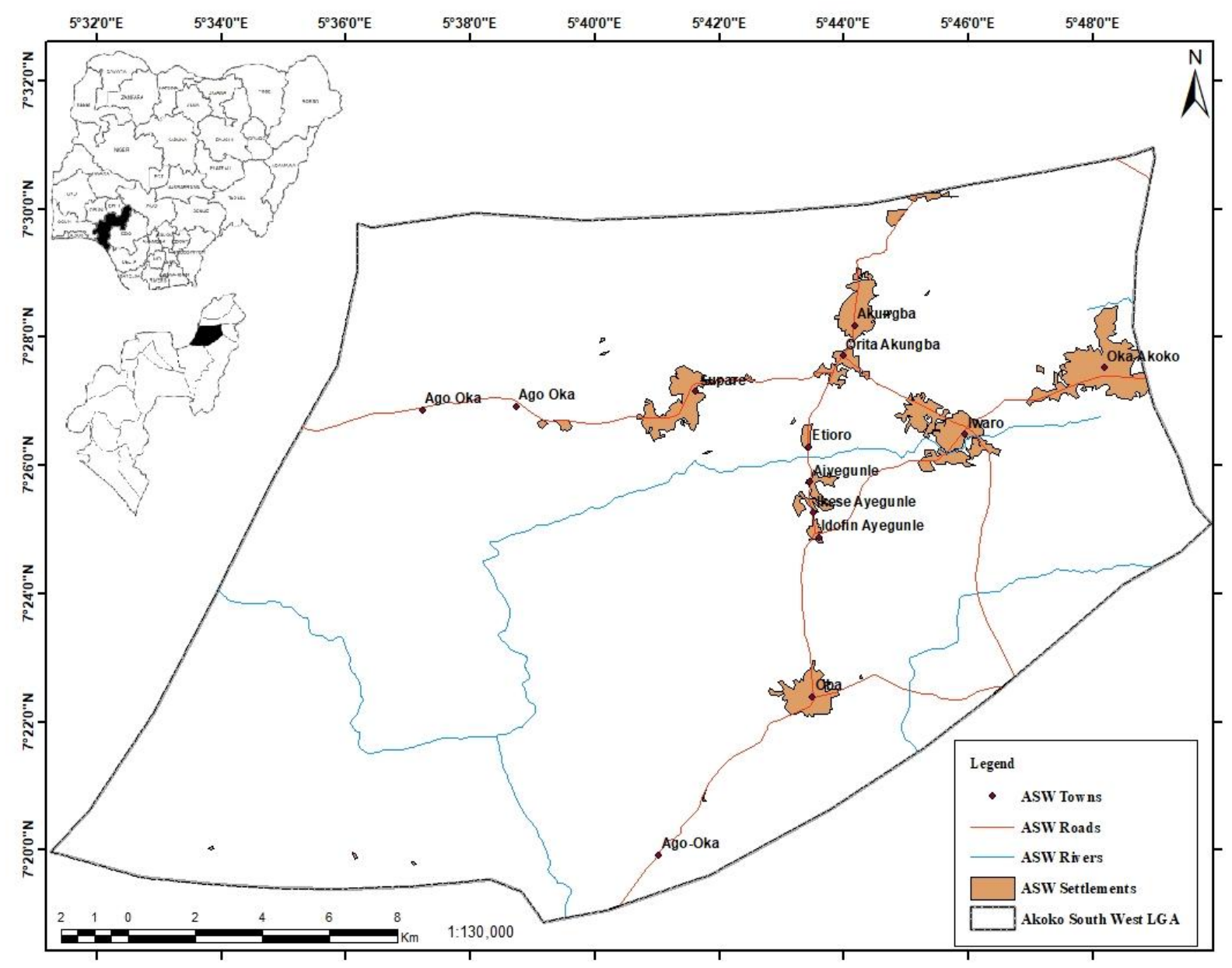

Fig. 1. The Administrative Map of the Study Area 


\section{METHODOLOGY}

Landsat images of three epochs of the study area for year 2000, 2010 and 2020 were downloaded from the Glovis website. The scan lines on the 2010 image were removed through the raster analysis in QGIS 3.18. The different scenes of the images at various epochs were subsetted into the area of interest using the Local Government administrative boundary of Nigeria obtained from the office of the Surveyor General of the Federation. ArcGIS 10.8 was used in image processing (colour composite and subsetting), analysis (image classification through maximum likelihood classifier, vectorisation and geometric calculations) and cartographic presentation of result. Statistical analysis was done using Microsoft office excel 2016.

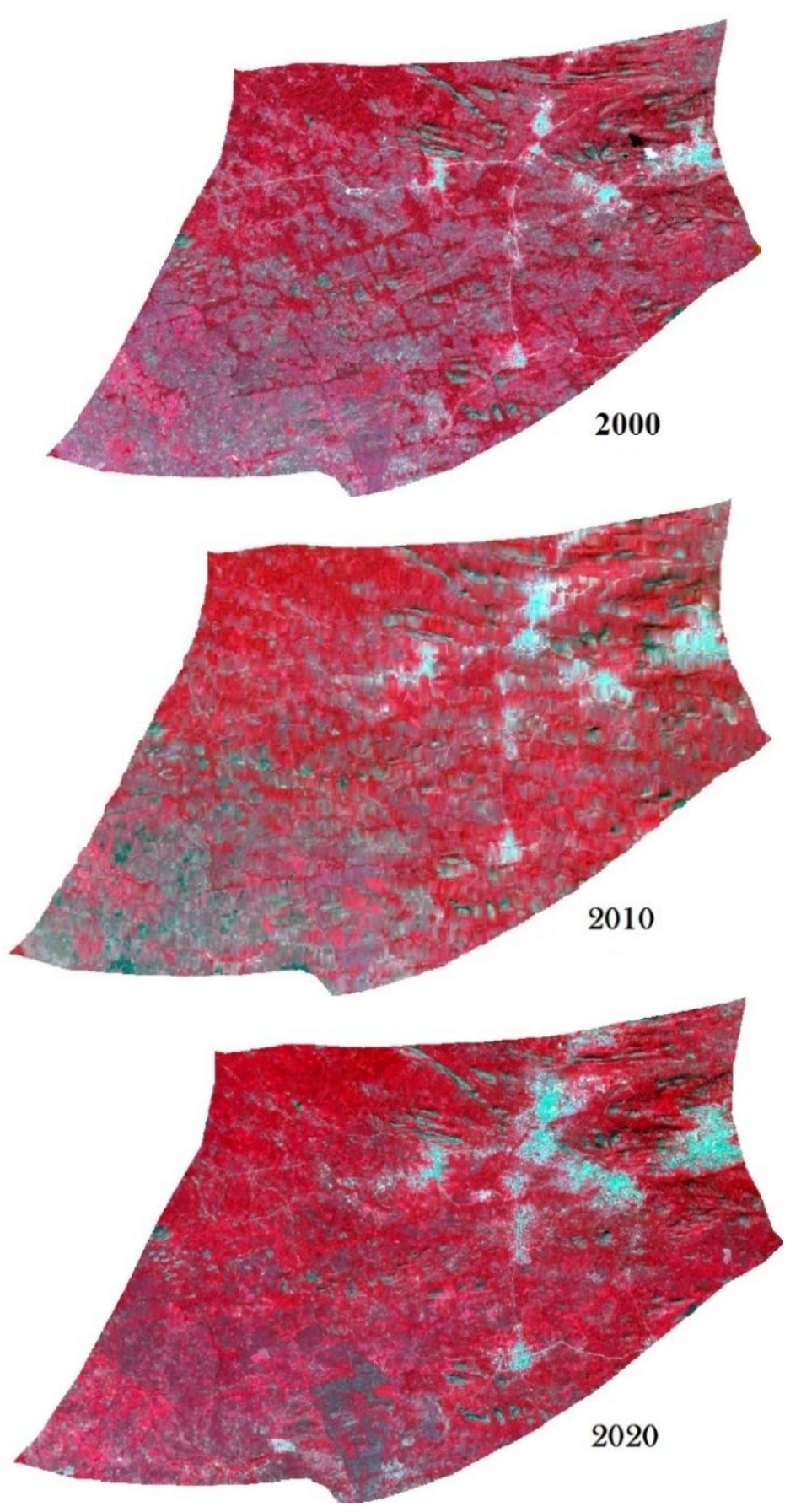

Fig. 2. Satellite Images of the Area of Interest at Various Epochs 


\section{- Land use/land Cover Distribution of the Study Area}

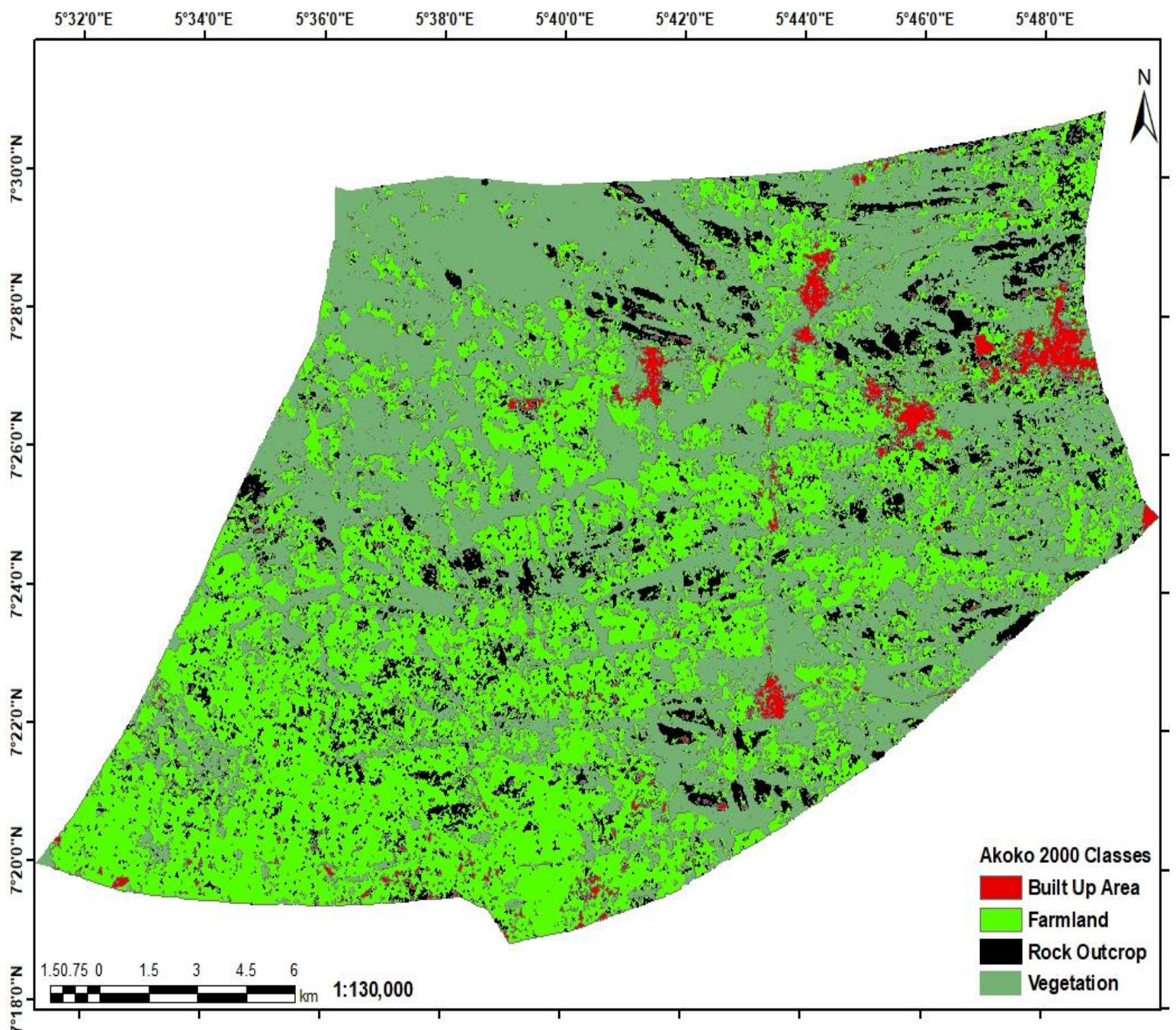

Fig. 3. Land use/land cover of the study area (2000)

\section{RESULT AND DISCUSSION}

Fig. 3-5 show the land use/cover of Akoko South West Local Government area in three epochs of 2000, 2010 and 2020. The land use/cover was produced at an overall accuracy of $92.11 \%$ and Kappa coefficient of 0.90 for 2020 datasets, $71.63 \%$ and 0.69 for 2010 dataset and $79.33 \%$ and 0.76 for 2000 dataset respectively.

Table 1. Land use/land cover distribution of the study area in square kilometers and percentages

\begin{tabular}{|c|c|c|c|c|c|c|}
\hline \multirow{2}{*}{$\begin{array}{l}\text { Land Use/Cover } \\
\text { Classes }\end{array}$} & \multicolumn{2}{|l|}{2000} & \multicolumn{2}{|l|}{2010} & \multicolumn{2}{|l|}{2020} \\
\hline & Area $\left(\mathrm{km}^{2}\right)$ & $\begin{array}{l}\text { Area } \\
(\%)\end{array}$ & Area $\left(\mathrm{km}^{2}\right)$ & $\begin{array}{l}\text { Area } \\
(\%)\end{array}$ & Area $\left(\mathrm{km}^{2}\right)$ & $\begin{array}{l}\text { Area } \\
\text { (\%) }\end{array}$ \\
\hline Built Up Area & 13 & 2.70 & 17 & 3.53 & 38 & 7.90 \\
\hline Farmland & 230 & 47.82 & 206 & 42.83 & 196 & 40.75 \\
\hline Rock Outcrop & 26 & 5.41 & 71 & 14.76 & 65 & 13.51 \\
\hline Vegetation & 212 & 44.07 & 187 & 38.88 & 182 & 37.84 \\
\hline Total & 481 & 100 & 481 & 100 & 481 & 100 \\
\hline
\end{tabular}


In year 2000, the built-up area which was the least occupied an area of $13 \mathrm{~km}^{2}$ which was equivalent to $2.7 \%$ of the study area while farmland utilized the highest percentage of $47.82 \%$ at $230 \mathrm{~km}^{2}$ owing to the fact that majority of the population are engaged in agriculture. The rock outcrop covered $26 \mathrm{~km}^{2}$ at $5.41 \%$ while the vegetation in the area absorbed $212 \mathrm{~km}^{2}$ at $44.07 \%$ being tropical savannah in nature Built up coverage enlarged to $17 \mathrm{~km}^{2}$ in 2010 and absorbed $3.53 \%$ of the total land area. This was followed by rock outcrops which engrossed $14.76 \%$ at $71 \mathrm{~km}^{2}$. There were reductions in farmland and vegetation which engaged $206 \mathrm{~km}^{2}$ $(42.83 \%)$ and $187 \mathrm{~km}^{2}(38.88 \%)$ respectively of the total area within the study period.

Year 2020 witnessed a tremendous growth (over $100 \%$ ) in built up area as it soared to $38 \mathrm{~km}^{2}$ $(7.90 \%)$. The trio of farmland, rock outcrop and vegetation contracted in the last epoch. This shrinking was influenced by the conversion of land use/cover from one form to the other. Farmland, rock outcrops and vegetation reduced to $196 \mathrm{~km}^{2}$ (40.75\%), $65 \mathrm{~km}^{2}$ (13.51\%) and 182 $\mathrm{km}^{2}(37.84 \%)$ respectively. Below is the bar chart of the land use/land cover of the study area at different epoch.

\subsection{Nature and Magnitude of Change in the Study Area}

Table 2 and Fig. 7 show the change distribution in the study area from 2000 to 2020. Within the period under investigation, it was observed that built up areas expanded from $4 \mathrm{~km}^{2}$ in the first epoch (2010-2000) to $21 \mathrm{~km}^{2}$ in the second epoch (2020- 2010). The change in the first epoch was not as high as the second. This change might be attributed to the corresponding increase in the population of the area. As the population grows, there is always the need for the provision of housing to shelter the populace.

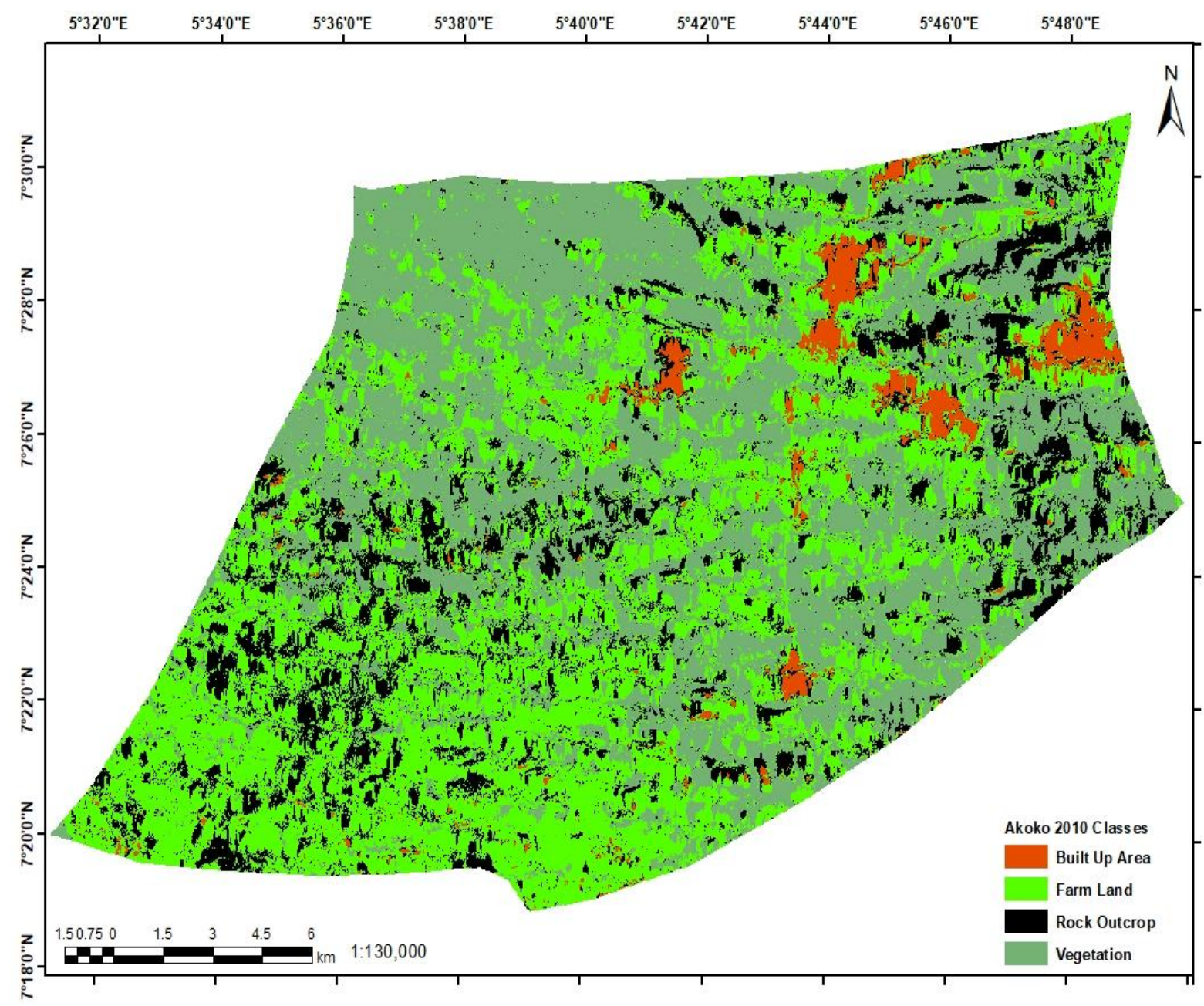

Fig. 4. Land use/land cover of the study area (2010) 


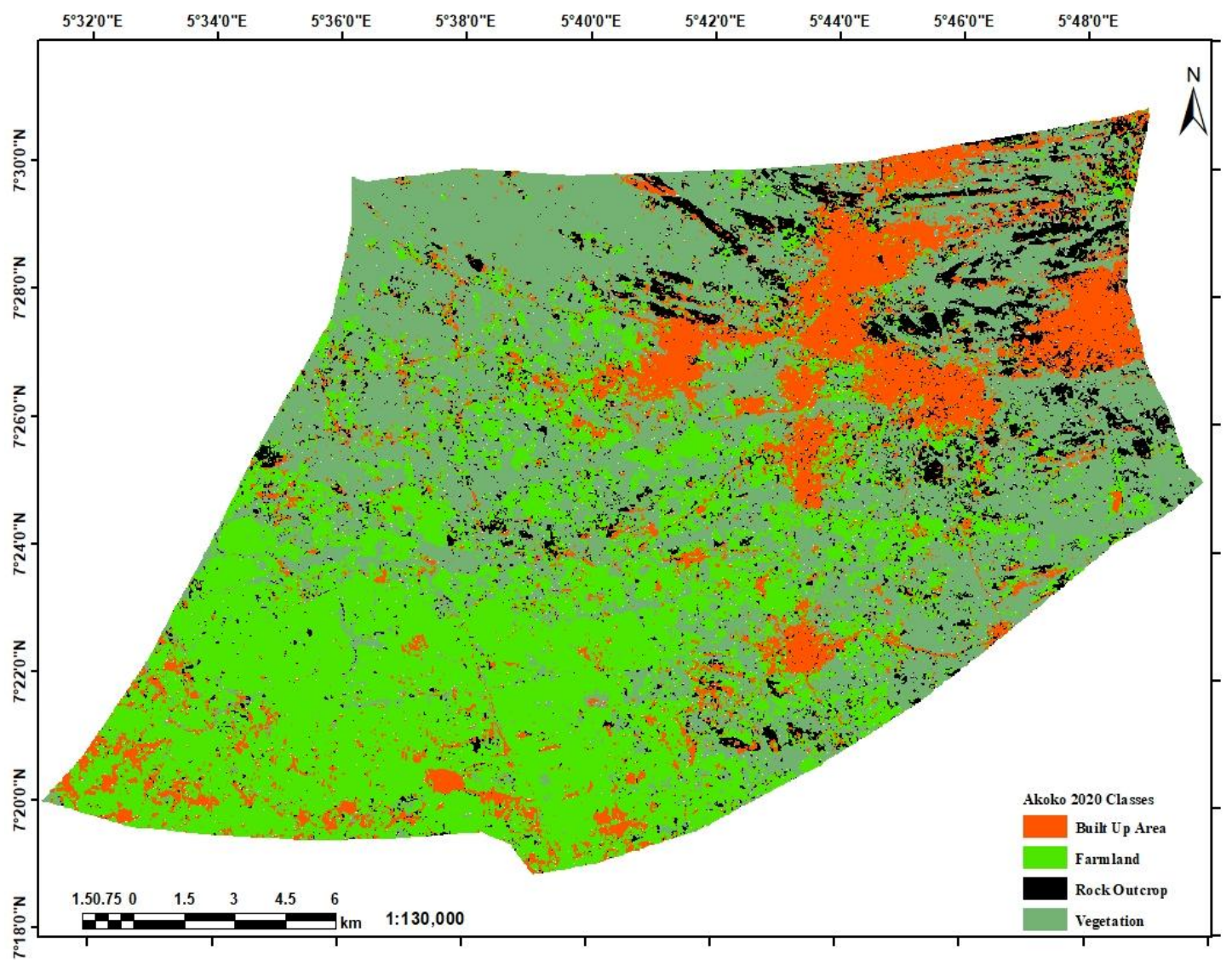

Fig. 5. Land use/land cover of the study area (2020)

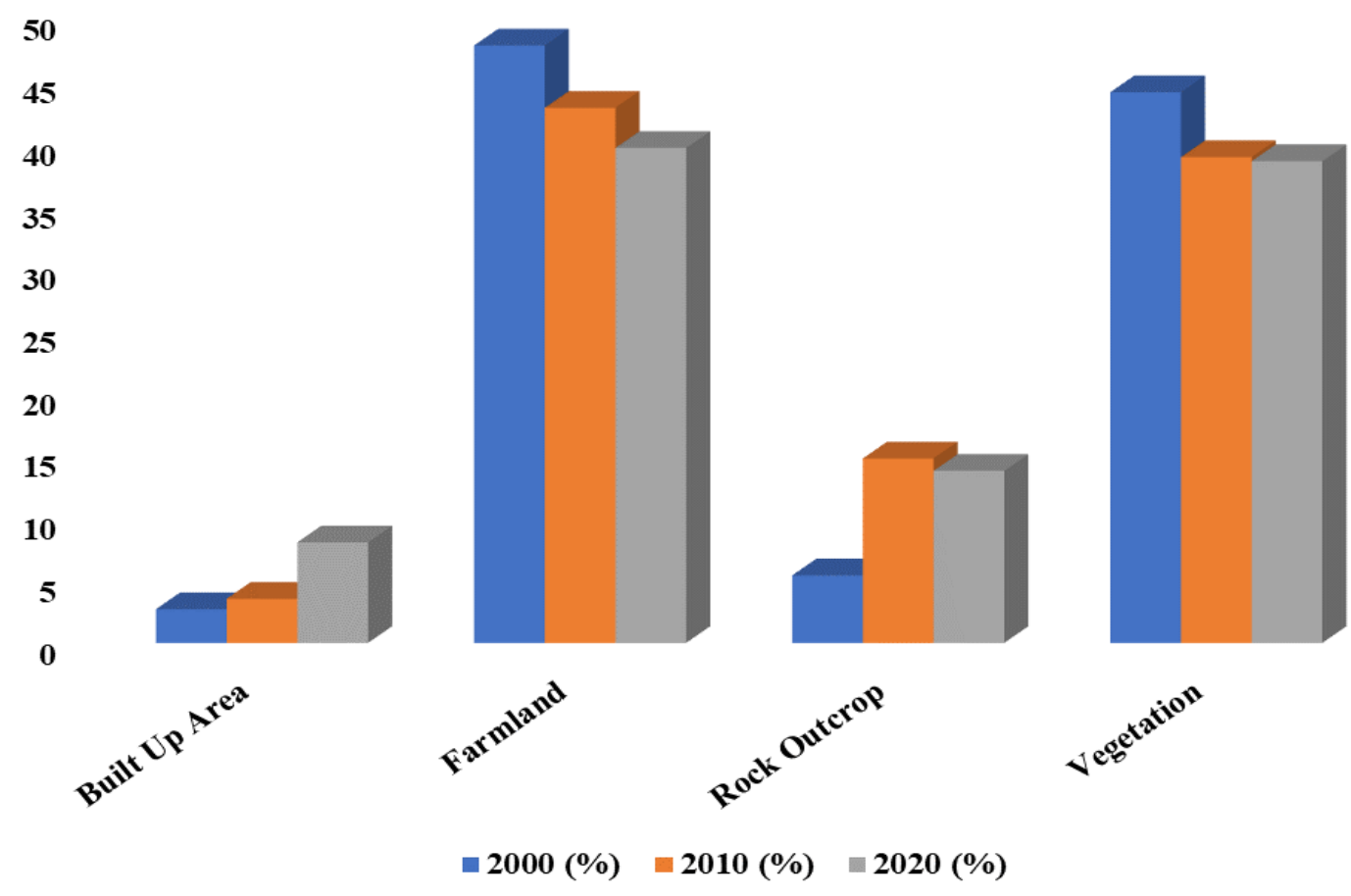

Fig. 6. Bar chart showing the Land use/land cover distribution of the study 
Table 2. Change trend of the study area

\begin{tabular}{|c|c|c|c|c|}
\hline \multirow[t]{2}{*}{ Land Use/Cover Classes } & \multicolumn{2}{|c|}{$2010-2000$} & \multicolumn{2}{|c|}{$2020-2010$} \\
\hline & sqkm & $\%$ & sqkm & $\%$ \\
\hline Built Up Area & 4 & 0.83 & 21 & 4.37 \\
\hline Farmland & -24 & -4.99 & -10 & -2.08 \\
\hline Rock Outcrop & 45 & 9.36 & -6 & -1.25 \\
\hline Vegetation & -25 & -5.20 & -5 & -1.04 \\
\hline \multicolumn{5}{|l|}{50} \\
\hline \multicolumn{5}{|l|}{40} \\
\hline \multicolumn{5}{|l|}{30} \\
\hline \multicolumn{5}{|l|}{20} \\
\hline \multicolumn{5}{|l|}{10} \\
\hline \multicolumn{5}{|l|}{$\mathbf{0}$} \\
\hline \multicolumn{5}{|l|}{-10} \\
\hline \multicolumn{5}{|l|}{-20} \\
\hline \multicolumn{5}{|l|}{ Built Un A rea } \\
\hline Built Up Area & Farmland & Rock Outcrop & Vegetation & \\
\hline - Chang & $0-2000$ (sq.km) & Change 2020 & 010 (sq.km) & \\
\hline
\end{tabular}

Fig. 7. Bar chart showing the dynamics of land use/land cover in the study area

Rock outcrop on the other hand gained in the first epoch and lost in the second epoch as a result of the use of granite for construction works in all the nooks and crannies of the study area. The increased in the first phase might be due to erosion and deforestation in the area which had exposed some of the rock outcrops. The use of this resource in almost all the construction works will definitely continue to reduce its coverage in the area in the nearest future.

Both farmland and vegetation were reduced in the two epochs. The reduction in both vegetation and farmland could be attributed to the anthropogenic activities of the increased population in the area. The reductions in farmlands and vegetation in the second epoch were not as high as the first epoch. Trees are being cut down continuously to meet up with other human induced activities in the area like furniture, roofing and fire/fuel wood consumption. Some of these vegetations are being converted to farmlands. Farmlands which are hitherto close to settlements are also converted to build up areas. The reduction in farmlands has reduced the land available for crop production. This has negative effect on food security. The reduced reduction in the vegetation in the second epoch might be attributed further to the policies of the state government in preserving the forest reserves of the area while the reduced reduction in farmland might be attributed to the diversification of the economy by the increasing population. Devegetation on the other hand exacerbate loss of biodiversity. In all, there was conversion of land use/land cover from one form to the other.

\subsection{Projection of Change}

This was done using the forecast function of the Microsoft office excel. By 2030, the built-up area is projected to cover about $47.67 \mathrm{~km}^{2}$ or $10.11 \%$ of the study area in increasing trend while the farmland and vegetation will cover $164.67 \mathrm{~km}^{2}$ $(36.69 \%)$ and $163.67 \mathrm{~km}^{2}(36.06 \%)$ respectively in reducing trend.

\section{CONCLUSION}

The study has shown that built up area in the study area is increasing while the vegetation and farmland are reducing. However, the change in the second epoch for built up was higher than the first epoch by over $100 \%$. The reduction in the farmland was attributed to the diversification of the economy of the citizens on other sources of 
income and the consumption of farmland for developmental purposes. The vegetation on the other hand got reduced due to illegal depletion of forest by man despite the government policy on forest reserve in the area. The study has further demonstrated the efficacy of geospatial technology in handling the assessment and mapping of the nature and trend of land use and land cover change dynamics in an area or a region.

\section{DISCLAIMER}

The products used for this research are commonly and predominantly use products in our area of research and country. There is absolutely no conflict of interest between the authors and producers of the products because we do not intend to use these products as an avenue for any litigation but for the advancement of knowledge. Also, the research was not funded by the producing company rather it was funded by personal efforts of the authors.

\section{COMPETING INTERESTS}

Authors have declared that no competing interests exist.

\section{REFERENCES}

1. Manjunatha MC, Basavarajappa HT. Geospatial approach for Mapping of Dynamic LU/LC Classification in Piriyapatna Taluk, Karnataka, India. International Advanced Research Journal in Science, Engineering and Technology. 2021;8(1).

DOI: $10.17148 / I A R J S E T .2021 .8104$

2. FAO. Land Cover Classification System; Classification Concepts. Software version 3; 2016.

3. Verburg $\mathrm{PH}$, Neumann $\mathrm{K}$, Nol $\mathrm{L}$. Challenges in using land use and land cover data for global change studies. Glob. Change Biol. 17:974-989. 2011;5(11):7996.

4. Zimmermann $\mathrm{P}$, Tasser $\mathrm{E}$, Leitinger $\mathrm{T}$, Tappeiner U. Effects of land-use and land- cover pattern on landscape-scale biodiversity in the European Alps. Agric. Ecosyst. Environ. 2010;139:13-22

5. Sreedhar Y, Nagaraju A, Krishna GM. An Appraisal of Land Use/Land Cover Change scenario of Tummalapalle, Cuddapah Region, India-A Remote Sensing and GIS Perspective. Advances in Remote Sensing. 2016;(5):232-245.

6. Basavarajappa HT, Dinakar S, Manjunatha MC. Analysis on land use/land cover classification around mysuru and chamarajanagara district, karnataka, india, using irs-1d pan+liss-iii satellite data. International Journal of Civil Engineering and Technology (IJCIET), detection using high resolution temporal satellite data. Journal of Environment. 2014;01(04):146152.

7. Ibilewa D. Vegetation and wetland resources mapping in Kuje Area Council, Federal Capital Territory (FCT), Abuja, Nigeria. Ethiopian Journal of Environmental Studies and Management. 2018;11(3):276 - 295

8. Fagbohunka A. Local Government Administration and the Development of Oba Akoko, Akoko South West Local Government, Ondo State, Nigeria. Asian Research Journal of Arts \& Social Sciences; 2019.

DOI: 10.9734/arjass/2019/v8i330099

9. Harshika A. Kaul and Ingle Sopan. Land use land cover classification and change; 2012.

Available:http://dx.doi.org/10.4236/ars.201 6.54019

10. Manjunatha MC, Basavarajappa HT, Jeevan L. Geomatics analysis on land use land cover classification system in precambrian terrain of chitradurga district karnataka, india. international Journal of Civil Engineering and Technology (ijciet). 2015;6(2).

11. Zubair Opeyemi A, Ji Wei and Festus Olusola. Urban Expansion and the Loss of Prairie and Agricultural Lands: A Satellite Remote-Sensing-Based Analysis at a SubWatershed Scale; 2019.

(c) 2021 Ibilewa et al.; This is an Open Access article distributed under the terms of the Creative Commons Attribution License (http://creativecommons.org/licenses/by/4.0), which permits unrestricted use, distribution, and reproduction in any medium, provided the original work is properly cited.

Peer-review history:

The peer review history for this paper can be accessed here: https://www.sdiarticle4.com/review-history/73461 